\title{
Factors Associated with Singleton Preterm Birth in Shire Suhul General Hospital, Northern Ethiopia, 2018
}

\author{
Bayew Kelkay (D), ${ }^{1}$ Awol Omer, ${ }^{2}$ Yelfu Teferi, ${ }^{2}$ and Yohannes Moges ${ }^{3}$ \\ ${ }^{1}$ School of Midwifery, College of Medicine and Health Science, University of Gondar, Gondar, Ethiopia \\ ${ }^{2}$ Department of Midwifery, College of Health Science and Comprehensive Specialized Hospital, Aksum University, Axum, Ethiopia \\ ${ }^{3}$ Department of Midwifery, Institute of Medicine and Health Science, Debre Berhan University, Debre Berhan, Ethiopia \\ Correspondence should be addressed to Bayew Kelkay; bayekelkay@yahoo.com
}

Received 4 January 2019; Revised 19 March 2019; Accepted 17 April 2019; Published 8 May 2019

Academic Editor: Jacques Balayla

Copyright (C) 2019 Bayew Kelkay et al. This is an open access article distributed under the Creative Commons Attribution License, which permits unrestricted use, distribution, and reproduction in any medium, provided the original work is properly cited.

\begin{abstract}
Background. Preterm birth is the leading cause of neonatal mortality and significant health consequences to the newborn, families, and communities and tens of emotional and economic costs. Therefore, the aim of this study was to assess the magnitude of singleton preterm birth and associated factors in Shire Suhul General Hospital, Northern Ethiopia. Methods. Institutional based cross-sectional study was conducted among systematically selected 325 postnatal mothers in Shire Suhul General Hospital, Northern Ethiopia, from January to March 2018. The data were collected through both face-to-face interview and chart review by using pretested semistructured questionnaires. SPSS version 20 was employed to enter and analyze the data. Both bivariate and multivariate logistic regression models were run to identify factors associated with singleton preterm birth at the level of $P$ values $\leq$ 0.25 and $<0.05$ for each model, respectively. Result. The magnitude of singleton preterm birth in Suhul Hospital was $16.9 \%$. Smoking cigarette/drinking alcohol during pregnancy [AOR=3.61: CI 95\%; 1.59-8.23], previous abortion [AOR=2.37: CI 95\%; 1.15-4.88], hemoglobin level < 1lgm/dl [AOR=2.44: CI 95\%; 1.14-5.22], visible physical neonatal congenital anomaly [AOR=10.42: CI 95\%; 1.66-65.23] , and history of giving low birth weight baby [AOR: 2.78 CI 95\%; 1.39-5.55] were the factors statistically associated with singleton preterm birth. Conclusion. The magnitude of preterm birth in this study was higher than the average prevalence of preterm birth reported in Ethiopia. Smoking cigarette/drinking alcohol during pregnancy, mothers who had previous abortion, low maternal hemoglobin level, presence of visible physical congenital anomalies of newborn baby, and history of bearing low birth weight baby were found to have statistically significant association with singleton preterm birth. Supplement of daily iron with folic acid (folic acid ideally before pregnancy) for all pregnant mothers with good adherence monitoring and giving attention to preconceptional health care service to avoid any cigarette smoking/alcohol drinking and risk detection were set as recommendations.
\end{abstract}

\section{Introduction}

The World Health Organization (WHO) defines preterm birth as a baby born too early or before 37 complete weeks of gestation from the first day of the last normal menstrual period (LNMP). Birth too soon is categorized as extremely preterm (less than 28 weeks), very preterm (28-32 weeks), and moderate to late preterm (32weeks to 36 weeks and 6 days). Preterm birth may happen spontaneously or is initiated by clinicians for different medical or nonmedical reasons and mothers deliver either single or multiple neonates. Globally, around 1 million children die each year due to complications of preterm birth and $60 \%$ of them occur in Africa and South Asia. Generally, the average rate of preterm birth in lower income countries and higher income countries is $12 \%$ and $9 \%$, respectively [1]. In Ethiopia, 320,000 premature babies are born each year and it directly contributes to 24,400 (12.5\%) deaths of under-five children [2].

Preterm birth is the major single burden for both developing and developed countries. Some of the anticipated complications following birth of preterm neonates are motor development, behavior and academic performance impairment, and even deaths within minutes $[3,4]$. Preterm birth often requires more resources for health care, social 
based rehabilitation service, special education placement, and specialized health care professionals throughout their childhood and even adulthood [5].

According to pieces of literature, several sociodemographic and fetomaternal factors have contributed to the overall rise in the prevalence of preterm birth. Experience of previous preterm delivery [6-9], mothers having inadequate prenatal visits [10-12], pregnancy that induced hypertension during pregnancy $[10,13,14]$, anemic mothers $[15,16]$, antepartum hemorrhage during the most recent pregnancy $[8-10,17]$, twin delivery in most recent birth [10], presence of fetal anomaly [18, 19], smoking [20, 21], and HIV positive mothers [14] were some of repeatedly associated factors with the occurrence of preterm birth.

A high epidemic of preterm birth and related newborn deaths is one of the greatest health challenges of these days. However, two-thirds of these complications and deaths could be prevented by simple inexpensive measures that do not need high technology $[22,23]$. In developed countries, treatment with metronidazole and erythromycin helps to prevent premature delivery caused by bacterial vaginosis [24] Using vaginal progesterone is the most efficacious and safe method to prevent preterm labor that leads to preterm birth [25].

However, preterm birth is a complex multifactorial process associated with diverse pathogenetic mechanisms. Most factors are usually prevented by simple strategies. Health care providers or other stakeholders who worked in this study setting need data related to common regional factors, since data limitation is there. Few studies conducted in Ethiopia are related to preterm birth. These studies were conducted by direct mothers' interview, and in the meantime, researchers have missed very important variables that need to be examined but valid data were accessible from maternal charts like maternal hemoglobin level, neonatal weight, gestational age determined by clinicians (using ultrasound or LNMP), and diagnosed medical diseases. Additionally, almost all studies included mothers who gave multiple (twin, triple, and higher) and singleton fetus indifferently. Meanwhile, multifetal pregnancies do not have an equal chance suffering for preterm birth compared to singleton birth due to physiological reasons. Therefore, answering the above issues and using it as input for the study area to conduct further studies were the aim of this study.

\section{Materials and Methods}

2.1. Study Design and Population. Institutional based crosssectional study was conducted from January to March 2018 with 325 mothers who gave birth in Shire Suhul General Hospital at the time of data collection. The study was conducted at Shire town, the capital of northwest zone of Tigray regional state located $1087 \mathrm{Kms}$ far from Addis Ababa (the capital city of Ethiopia) and $357 \mathrm{Kms}$ from Mekelle (the capital of Tigray regional state). Based on the reports from the zonal administrative office, the town has 67,243 total populations; among these, 36,146 are females. In Suhul General Hospital, the total annual birth report in 2017/18 was 3,048 and the first quarter (July-October) birth was 720 .
2.2. Inclusion and Exclusion Criteria. Mothers who gave birth and had known either LNMP or 1st trimester ultrasound diagnosis were included for this study.

2.3. Sample Size and Sampling Technique. Sample size for this study was calculated by using single population proportion formula with the assumption of $95 \%$ confidence level, $25.9 \%$ prevalence of preterm birth [19], and 5\% marginal error. The final sample size after considering $10 \%$ of nonresponse rate was 325 . Finally, a systematic random sampling technique with sampling interval $\left(\mathrm{K}^{\text {th }}\right)$ value of two (2) was used to identify interviewed participants. The first study participant was selected randomly and continued every two intervals.

\subsection{Study Variables}

2.4.1. Dependent Variable. Singleton preterm birth refers to a mother who gave one baby with gestational age $<37$ weeks or before 259 complete days.

2.4.2. Independent Variables. Sociodemographic variables are age, marital status, religion, residence, occupation, and educational status. Maternal factors (obstetrical \& medical) are parity, gestational age of current baby in weeks, medication intake during the most recent pregnancy, smoking cigarette/drinking alcohol during the most recent pregnancy, history of hyperemesis-gravidarum in the most recent pregnancy, previous abortion, previous stillbirth, previous preterm birth, previous cesarean delivery, history of vaginal bleeding during the most recent pregnancy (antepartum hemorrhage), history of diagnosed urinary tract infection in the most recent pregnancy, hypertension disorder during the most recent pregnancy, history of hospitalization during the most recent pregnancy, previous diagnosed fibroid, maternal current serostatus, level of the most recent hemoglobin, previous malaria attack, mode of delivery of the current baby, history of ANC (antenatal care) follow-up, number of ANC follow-ups, and birth (interdelivery) interval. Fetal factors are congenital abnormalities of the current newborn, previous multiple delivery, giving congenitally defected baby, and history of giving LBW (low birth weight) baby including the most recent and sex of the current newborn.

2.5. Data Collection and Quality Control. The data were collected by using a pretested semistructured questionnaire through both face-to-face interview and extracting (review) respective mothers' chart for necessary data. Questionnaires were prepared first in English after reviewing different works of literatures and translated into local language (Tigrigna) and then back to English by the third party who was native in Tigrigna to ensure consistency. The data collection was carried out within 24 hours before mothers going to be discharged. Four midwives who were fluent in local language were involved in data collection. Detail orientation was provided for data collectors.

2.6. Data Processing and Analysis. Collected data were entered and cleaned and analysis was by SPSS version 20 . 


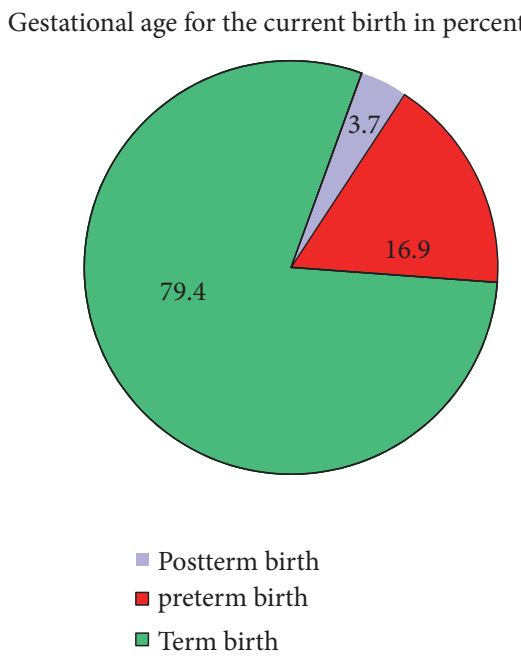

Figure 1: Gestational age of newly born neonates in Shire Suhul General Hospital, Northwest Tigray, Ethiopia, 2018 (N=325).

Descriptive statistics were summarized into frequency and proportion. Both bivariate and multivariate analysis model were run to check the association between dependent and independent variables. All variables with $P$ value $\leq 0.25$ in bivariate analysis were taken into multivariate logistic regression model and variables having $P$ value $<0.05$ with 95\% CI declared factors significant association with singleton preterm birth.

\section{Result}

3.1. Sociodemographic Characteristics. A total of 325 mothers participated in this study with $100 \%$ response rate. Two hundred seventy-three (84\%) of the participants were of age $<35$ years with the mean age of 27.88 years \pm 5 years of SD. More than three-fourths $(88.6 \%)$ of the study participants were Orthodox Christian followers and majority, 306(94.2\%), were married.

More than half $(57.8 \%)$ of the mothers were from the urban area and $201(61.8 \%)$ of them were the housewives in occupational status. More than three-fourths, 252 (77.5\%), were primary school and less in their educational status. Family size of more than half, 189 (58.2\%), of the mothers was within the range of 2-4 individuals. Almost all, 304 (93.5\%), mothers have never suffered from hard workload in the most recent pregnancy and 91 (28\%) participants' monthly income was within the range of 1401-2350 Ethiopian Birr ( see Table 1).

3.2. Maternal (Obstetrical and Medical) Factors. According to this study, greater than three-fourths of the study participants gave term neonates followed by $16.9 \%$ of preterm birth (see Figure 1).

Nearly half, $167(51.4 \%)$, gave within the range of $2-4$ viable babies (multipara) before the study period. More than $80 \%$ of the study participants have never had the history of medication intake, drinking alcohol/smoking cigarette, vaginal bleeding after fetal viability $(\mathrm{APH})$, urinary tract infection, hypertension, hospital admission, and hyperemesisgravidarum in most recent pregnancy. Two hundred sixtyeight (82.5\%), 284 (87.4\%), 282 (86.8\%), 295 (90.8\%), and 310 (95.4\%) had no history of abortion, stillbirth, preterm birth, cesarean delivery, and fibroids (uterine mass) in previous pregnancies.

Among the study participants, 16 (4.9\%) were reactive in HIV/AIDS, 91 (24.9\%) were attacked by malaria, and 48 (14.8\%) mothers' hemoglobin levels were $<11 \mathrm{gm} / \mathrm{dl}$. Of 325 study participants, 256 (78.8\%) mothers gave birth vaginally and most, 134 (41.2\%), of them had average interval of birth between 1 and 3 years. Almost all, 302 (92.9\%), of the study participants had the history of ANC follow-up during the recent pregnancy and from those majority, 245(81.1\%), had $\geq 4$ contacts (see Table 2 ).

3.3. Fetal Factor. Among newborns who were delivered during the study period, only $6(1.8 \%)$ mothers gave congenital abnormal babies whereas $17(5.2 \%)$ of the respondents had a previous history of giving congenital anomalies baby. Including the most recent births, 60 (18.5\%) of the study participants had the history of having low birth weight baby. More than half, 183 (56.3\%), neonates were female (see Table 3).

3.4. Factors Associated with Singleton Preterm Birth. All independent variables were analyzed using binary logistic regressions and all variables with $P$ value $\leq 0.25$ were fitted to run in multivariate logistic regression. Finally, in multivariate logistic regression model, smoking cigarette/drinking alcohol during the most recent pregnancy, history of abortion, hemoglobin level, a physical congenital defect in the most recent baby, and history of bearing low birth weight baby including the most recent one were identified as independently associated variables with singleton preterm birth at $P$ value $<0.05$ 
TABLE 1: Sociodemographic characteristics of respondents in Shire Suhul General Hospital, Northwest Tigray, Ethiopia, 2018 (n=325).

\begin{tabular}{|c|c|c|c|}
\hline Variables & Variable category & Frequency & Percent $(\%)$ \\
\hline \multirow{2}{*}{ Age in year } & $<35$ & 273 & 84 \\
\hline & $\geq 35$ & 52 & 16 \\
\hline \multirow{4}{*}{ Marital status } & Single & 13 & 4 \\
\hline & Married & 306 & 94.2 \\
\hline & Widowed & 4 & 1.2 \\
\hline & Divorced & 2 & 0.6 \\
\hline \multirow{3}{*}{ Religion } & Orthodox & 288 & 88.6 \\
\hline & Muslim & 35 & 10.8 \\
\hline & Protestant & 2 & 0.6 \\
\hline \multirow{2}{*}{ Residence } & Rural & 137 & 42.2 \\
\hline & Urban & 188 & 57.8 \\
\hline \multirow{4}{*}{ Occupation } & Student & 15 & 4.6 \\
\hline & Merchants & 64 & 19.7 \\
\hline & Housewife & 201 & 61.8 \\
\hline & Governmental workers & 47 & 14.5 \\
\hline \multirow{3}{*}{ Educational status } & Primary or less & 252 & 77.5 \\
\hline & Secondary education & 10 & 3.1 \\
\hline & Postsecondary education & 63 & 19.4 \\
\hline \multirow{2}{*}{ Family size } & $2-4$ & 189 & 58.2 \\
\hline & $>=5$ & 136 & 41.8 \\
\hline \multirow{2}{*}{ Suffering from a heavy workload } & Yes & 21 & 6.5 \\
\hline & No & 304 & 93.5 \\
\hline \multirow{6}{*}{ Monthly income of the family in birr } & $150-650$ & 50 & 15.4 \\
\hline & $651-1400$ & 74 & 22.8 \\
\hline & $1401-2350$ & 91 & 28 \\
\hline & $2351-3550$ & 65 & 20 \\
\hline & $3551-5000$ & 29 & 8.9 \\
\hline & $>5000$ & 16 & 4.9 \\
\hline
\end{tabular}

Mothers who smoked cigarette/drank alcohol during the most recent pregnancy were 3.6 times more likely to have a preterm delivery than those who did not smoke/drink [AOR=3.6; 95\%CI: 1.59-8.23]. Similarly, mothers who had a history of abortion were nearly 2.4 times more likely to give preterm baby than their counterparts $[\mathrm{AOR}=2.37$; $95 \% \mathrm{CI}$ : 1.15-4.88].

Mothers whose most recent hemoglobin level was $<11$ $\mathrm{gm} / \mathrm{dl}$ were 2.4 times more risky for preterm birth as compared to those whose hemoglobin level was $\geq 11 \mathrm{gm} / \mathrm{dl}$ [AOR=2.44; 95\%CI: 1.14-5.22]. Finally mothers who gave neonates with physical congenital defect and who had history of delivering low birth weight baby including the most recent birth were statistically significant with singleton premature birth compared to their counterparts [AOR $=10.4 ; 95 \% \mathrm{CI}$ : 1.66-65.2] and [ $\mathrm{AOR}=2.78 ; 95 \% \mathrm{CI}: 1.39-5.55]$, respectively ( see Table 4).

\section{Discussions}

This study revealed that the prevalence of preterm birth was $16.9 \%$. This finding is in line with those studies conducted in India $18.01 \%$ [26], Nigeria 16.8\% [27], Malawi 16.3\% [16],
Tanzania $14.2 \%$ [12], and Kenya $18.3 \%$ [9]. This similarity could be due to some related leveled socioeconomic status and lifestyle among participants since all are developing countries.

This finding is higher than the average rate of preterm birth in lower income countries reported by WHO 12\% [28], Brazil 12.3\% [29], Iran 5.1\% [7], Australia 6.8\% [21], Debre Markos 11.6\% [30], Gondar 4.4\% [14], average Ethiopian prematurity birth $10 \%$ [23], and Tigray $8.1 \%$ [31]. This disparity could be due to this study setting having low access to quality of health care this study carried being out in single hospital and small sample participants involved in this study. However, most studies conducted in the above regions were case-control, involved multiple institutions, and used a large sample size.

On the other side, the magnitude of preterm birth in this study was much lower than the study carried out in India 25.6\% [32], Indonesia 35\% [15], and Jimma University Specialized Hospital 25.9\% [19]. This variation might be due to the fact that multiple pregnancies were not included in this study, nature of study areas, and health-seeking behavior among the study participants. 
TABLE 2: Obstetrical and medical characteristics of the respondents in Shire Suhul General Hospital, Northwest Tigray, Ethiopia, 2018 (n=325).

\begin{tabular}{|c|c|c|c|}
\hline Variables & variable category & Frequency & Percent \\
\hline \multirow{3}{*}{ Parity } & Para 1 & 103 & 31.7 \\
\hline & Para 2-4 & 167 & 51.4 \\
\hline & Para $\geq 5$ & 55 & 16.9 \\
\hline \multirow{3}{*}{ GA of the most recent pregnancy } & $<37$ weeks & 55 & 16.9 \\
\hline & $37-41^{+6}$ wks & 258 & 79.4 \\
\hline & $\geq 42$ weeks & 12 & 3.7 \\
\hline \multirow{2}{*}{ History of medication intake during the most recent pregnancy } & Yes & 57 & 17.5 \\
\hline & No & 268 & 82.5 \\
\hline \multirow{2}{*}{ History of smoking cigarette/drinking alcohol during the most recent pregnancy } & Yes & 33 & 10.2 \\
\hline & No & 292 & 89.8 \\
\hline \multirow{2}{*}{ History of hyperemesis gravidarum in the most recent pregnancy } & Yes & 64 & 19.7 \\
\hline & No & 261 & 80.3 \\
\hline \multirow{2}{*}{ History of abortion } & Yes & 57 & 17.5 \\
\hline & No & 268 & 82.5 \\
\hline \multirow{2}{*}{ History of stillbirth } & Yes & 41 & 12.6 \\
\hline & No & 284 & 87.4 \\
\hline \multirow{2}{*}{ History of preterm birth in previous pregnancies } & Yes & 43 & 13.2 \\
\hline & No & 282 & 86.8 \\
\hline \multirow{2}{*}{ History of Cesarean delivery } & Yes & 30 & 9.2 \\
\hline & No & 295 & 90.8 \\
\hline \multirow{2}{*}{ History of vaginal bleeding during the most recent pregnancy(Ante-partum hemorrhage) } & Yes & 30 & 9.2 \\
\hline & No & 295 & 86.8 \\
\hline \multirow{2}{*}{ History of diagnosed urinary tract infection in most recent pregnancy } & Yes & 17 & 5.2 \\
\hline & No & 308 & 94.8 \\
\hline \multirow{2}{*}{ History of hypertension during the most recent pregnancy } & Yes & 20 & 6.2 \\
\hline & No & 305 & 93.8 \\
\hline \multirow{2}{*}{ Hospitalization during the most recent pregnancy } & Yes & 29 & 8.9 \\
\hline & No & 296 & 91.1 \\
\hline \multirow{2}{*}{ History of diagnosed fibroid(uterine mass) } & Yes & 15 & 4.6 \\
\hline & No & 310 & 95.4 \\
\hline \multirow{2}{*}{ Maternal serostatus (HIV/AIDS) } & Positive & 16 & 4.9 \\
\hline & Negative & 309 & 95.1 \\
\hline \multirow{2}{*}{ The most recent maternal Hgb level in mg/dl } & $<11 \mathrm{mg} / \mathrm{dl}$ & 48 & 14.8 \\
\hline & $>=11 \mathrm{mg} / \mathrm{dl}$ & 277 & 85.2 \\
\hline \multirow{2}{*}{ History of malaria attack } & Yes & 91 & 24.9 \\
\hline & No & 244 & 75.1 \\
\hline \multirow{2}{*}{ Mode of delivery for the most recent birth } & Vaginal & 256 & 78.8 \\
\hline & Cesarean & 69 & 21.2 \\
\hline \multirow{3}{*}{ Birth interval in years } & $1-3$ & 134 & 41.2 \\
\hline & $>3$ & 120 & 36.9 \\
\hline & First baby & 71 & 21.8 \\
\hline \multirow{2}{*}{ ANC follow-up for the most recent Pregnancy } & Yes & 302 & 92.9 \\
\hline & No & 23 & 7.1 \\
\hline \multirow{2}{*}{ If 'Yes' number of visits( $n=302)$} & $<4$ visits & 57 & 18.9 \\
\hline & $>=4$ visits & 245 & 81.1 \\
\hline
\end{tabular}

* ANC; Antenatal care, Hgb; Hemoglobin, GA; Gestational age and HIV; Human immune deficiency virus.

* Medication/drug intake (any amount and type) when she was pregnant in that baby. 
TABle 3: Fetal characteristics of the respondents in Shire Suhul General Hospital, Northwest Tigray, Ethiopia, 2018 ( $\mathrm{n}=325)$.

\begin{tabular}{|c|c|c|c|}
\hline Variables & variable category & Frequency & Percent \\
\hline \multirow{2}{*}{ Congenital abnormality of current newborn } & Yes & 6 & 1.8 \\
\hline & No & 319 & 98.2 \\
\hline \multirow{2}{*}{ Previous multiple deliveries } & Yes & 30 & 9.2 \\
\hline & No & 295 & 90.2 \\
\hline \multirow{2}{*}{ Previous history of congenital abnormality } & Yes & 17 & 5.2 \\
\hline & No & 308 & 94.8 \\
\hline \multirow{2}{*}{ History of LBW including current newborn } & Yes & 60 & 18.5 \\
\hline & No & 265 & 81.5 \\
\hline \multirow{2}{*}{ Sex of newborn } & Male & 142 & 43.7 \\
\hline & Female & 183 & 56.3 \\
\hline
\end{tabular}

*LBW; Low birth weight

TABLE 4: Bivariate and multivariate factors associated with singleton preterm birth in Shire Suhul General Hospital, Northwest Tigray, Ethiopia, $2018(\mathrm{n}=325)$.

\begin{tabular}{|c|c|c|c|c|c|}
\hline \multirow{2}{*}{ Variables $(\mathrm{n}=325)$} & & \multicolumn{2}{|c|}{ Preterm birth } & \multirow{2}{*}{$\mathrm{COR}(95 \% \mathrm{CI})$} & \multirow{2}{*}{$\operatorname{AOR}(95 \% \mathrm{CI})$} \\
\hline & & No & Yes & & \\
\hline \multirow{3}{*}{ Parity } & $\mathrm{P} \geq 5$ & $39(70.9 \%)$ & $16(29.1 \%)$ & 1.00 & - \\
\hline & P 2-4 & $145(86.8 \%)$ & $22(13.2 \%)$ & & \\
\hline & Primipara & $86(83.5 \%)$ & $17(16.5 \%)$ & 0.48 [0.18-0.77] & $0.78[0.32-1.91]$ \\
\hline \multirow{2}{*}{ Medication intake } & No & $230(85.8 \%)$ & $38(14.2 \%)$ & 1.00 & - \\
\hline & Yes & $40(70.2 \%)$ & $17(29.8 \%)$ & 2.57 [1.33-4.99] & 0.8 [0.32-1.99] \\
\hline \multirow{2}{*}{ Smoked cigarette/drank alcohol } & No & $251(86.0 \%)$ & $41(14 \%)$ & 1.00 & - \\
\hline & Yes & 19(57.6\%) & $14(42.4 \%)$ & $4.51[2.10-9.70]$ & $3.61[1.59-8.23] * *$ \\
\hline \multirow{2}{*}{ Hyper-emesis- gravidarum } & No & $225(86.2 \%)$ & $36(13.8 \%)$ & 1.00 & - \\
\hline & Yes & $45(70.3 \%)$ & $19(29.7 \%)$ & $2.64[1.39-5.011]$ & $1.08[0.44-2.66]$ \\
\hline \multirow{2}{*}{ History of abortion } & No & $233(86.9 \%)$ & $35(13.1 \%)$ & 1.00 & - \\
\hline & Yes & $37(64.9 \%)$ & $20(35.1 \%)$ & $3.61[1.88-6.89]$ & $2.37[1.15-4.88] * *$ \\
\hline \multirow{2}{*}{ History of stillbirth } & No & $244(85.9 \%)$ & $40(14.1 \%)$ & 1.00 & \\
\hline & Yes & $26(63.4 \%)$ & $15(36.6 \%)$ & $3.52[1.72-7.22]$ & $0.85[0.28-2.65]$ \\
\hline \multirow{2}{*}{ History of preterm } & No & $244(86.5 \%)$ & $38(13.5 \%)$ & 1.00 & \\
\hline & Yes & $26(60.5 \%)$ & $17(39.5 \%)$ & $4.2[2.084-8.45]$ & $1.64[0.67-3.99]$ \\
\hline \multirow{2}{*}{ History of Vaginal bleeding } & No & $253(85.8 \%)$ & $42(14.2 \%)$ & 1.00 & \\
\hline & Yes & $17(56.7 \%)$ & $17(43.3 \%)$ & $4.61[2.09-10.18]$ & $1.51[0.50-4.55]$ \\
\hline \multirow{2}{*}{ Hospital admission } & No & $251(84.8 \%)$ & $45(15.2 \%)$ & 1.00 & \\
\hline & Yes & $19(65.5 \%)$ & $10(34.5 \%)$ & $2.94[1.28-6.73]$ & $1.06[0.35-3.25]$ \\
\hline \multirow{2}{*}{ Hemoglobin level before birth } & $\geq 11 \mathrm{gm} / \mathrm{dl}$ & $238(85.9 \%)$ & $39(14.1 \%)$ & 1.00 & \\
\hline & $<1 \operatorname{lgm} / \mathrm{dl}$ & $32(66.7 \%)$ & $16(33.3 \%)$ & $3.05[1.53-6.08]$ & $2.44[1.14-5.22] * *$ \\
\hline \multirow{2}{*}{ History of Malaria attack } & No & $211(86.5 \%)$ & $33(13.5 \%)$ & 1.00 & \\
\hline & Yes & $59(72.8 \%)$ & $22(27.2 \%)$ & $2.38[1.29-4.40]$ & $1.68[0.85-3.34]$ \\
\hline \multirow{2}{*}{ Number of ANC visits $(\mathrm{N}=302)$} & $\geq 4$ visits & $229(86.7 \%)$ & $35(13.3 \%)$ & 1.00 & \\
\hline & $<4$ visits & $41(67.2 \%)$ & $20(32.8 \%)$ & $3.19[1.68-6.07]$ & $1.43[0.64-3.20]$ \\
\hline \multirow{2}{*}{ Visible physical Congenital defect } & No & $268(84.0 \%)$ & $51(16.0 \%)$ & 1.00 & \\
\hline & Yes & $2(33.3 \%)$ & $4(66.7 \%)$ & $10.51[1.88-58.90]$ & $10.42[1.66-65.23] * *$ \\
\hline \multirow{2}{*}{ LBW } & No & $231(87.2 \%)$ & $34(12.8 \%)$ & & \\
\hline & Yes & $39(65.0 \%)$ & $21(35.0 \%)$ & $3.66[1.93-6.95]$ & $2.78[1.39-5.55] * *$ \\
\hline
\end{tabular}

* ANC: Antenatal care, P: Parity and LBW: Low Birth Weight

$* * \mathrm{P}$ value $<0.05$ and significantly associated. 
Mothers who smoked cigarette/drank alcohol during the most recent pregnancy experienced preterm birth more than those who never smoked/drank [AOR=3.61; 95\%CI: 1.598.23]. This finding was consistent with that of the study conducted in China, Australia, and Jimma [19-21]. This could be explained by the fact that cigarette/alcohol may interfere with the nutritional process and affect the strength of the membrane negatively that leads to premature rupture of the membrane. Mothers who had previous history of abortion were also 2.4 times more likely to give preterm baby [AOR $=2.37$; 95\%CI: $1.15-4.88]$ than those who never had. This is in agreement with the study conducted in Iran, Tanzania, and Jimma $[12,17,19]$. This finding could be explained by the fact that infection following the procedure may result in intra-amniotic infection and possibly idiopathic risk factor for preterm premature rupture of membrane and then result in preterm labor.

Mothers whose most recent hemoglobin levels $<11 \mathrm{gm} / \mathrm{dl}$ were nearly 2.5 times more likely to experience preterm birth compared to those $\geq 11 \mathrm{gm} / \mathrm{dl}$ [AOR=2.44; 95\%CI: 1.14-5.22]. This figure is in line with WHO 2013 report and the studies carried out in India, Indonesia, Malawi, and Debre Markos $[13,15,16,30,32]$. This could be explained biologically, anemia $(<11 \mathrm{gm} / \mathrm{dl})$ cause for hypoxia which can induce maternal and fetal stress, which stimulate the production of the corticotrophin-releasing hormone to lead the initiation of preterm labor.

Visible physical neonatal congenital anomalies in the most recent baby increased odds of the preterm birth occurrence compared to normal babies with $[\mathrm{AOR}=10.4$; 95\%CI: 1.66-65.2]. This finding was consistent with that of the study conducted in the United States of America, Palestine, and Jimma [11, 18, 19]. This could be because of clinicians who intended to initiate the labor artificially as soon as they detected congenital anomalies fetus who will not be compatible in life irrespective of gestational age. Mothers who had the previous history (including the most recent) of bearing neonatal weight $<2500$ gm were 2.8 fold more likely to give preterm baby compared to their counterparts. This finding was similar to the study carried out in Tanzania [12]. The possible reason related to indirect relations was because that problems with the placenta and maternal infection which could prevent oxygen and nutrients to reach the fetus result in both preterm and low birth weight baby.

\section{Limitation of the Study}

The study was conducted with a small sample size, only in one institution, and used maternal charts as additional data source which could result in overreporting and difficulty in inferring the entire society. Additionally, we failed to assess hypertension disorders during pregnancy separately as preeclampsia, eclampsia, gestational hypertension, and superimposed preeclampsia. Finally, the study design was cross-sectional, which did not show the causality of the limitations of this study.

\section{Conclusion}

The magnitude of preterm birth in this study was higher than the average prevalence of preterm birth reported in Ethiopia. Substance intake during pregnancy, previous abortion, low maternal hemoglobin level, the presence of visible physical congenital anomalies of newborn baby, and history of bearing low birth weight baby had statistically significant association with preterm birth. Supplement of daily iron with folic acid (folic acid ideally before pregnancy) for all pregnant mothers with good adherence monitoring and giving attention to preconceptional health care service to avoid cigarette/alcohol intake, and risk detection were set as recommendations.

\section{Abbreviation \\ AOR: Adjusted odds ratio \\ ANC: Antenatal care \\ COR: Crude odds ratio \\ LNMP: Last normal menstrual period \\ SPSS: Statistical package for social sciences \\ WHO: World Health Organization.}

\section{Data Availability}

The data used to support the findings of this study are available from the corresponding author upon request.

\section{Ethical Approval}

Our study received ethical approval from an institutional review board of Aksum University, College of Health Science and Comprehensive Specialized Hospital (Ref No AK/UN/R/H/CARD/mid/973/10). Suhul hospital administrative office also gave the permission and letter of approval submitted to the maternity to carry out the study.

\section{Consent}

Verbal consent was taken from the study participants after explaining the purpose of the study. Confidentiality was assured by using codes and interviewing alone with privacy. Participants were informed about the right not to participate in or withdraw from the study at any time through the interviews.

\section{Conflicts of Interest}

The authors confirm that they have no conflicts of interest in this work.

\section{Authors' Contributions}

Awol Omer and Yelfu Teferi supervised data collection and were involved in data cleaning and analysis. Yohannes Moges interpreted the data and was involved in methodology writing and manuscript preparation. Finally, all authors read and approved the manuscript. 


\section{Acknowledgments}

All authors are so grateful to Aksum University for ethical approval. Our heartfelt gratitude also extends to study participants for their clear and patient response upon the interview. Last but not least, our appreciation passes to midwives who worked in the maternity unit for their assistance to extract the data from mothers chart.

\section{References}

[1] WHO, "World health organization report about preterm birth," http://www.who.int/en/news-room/fact-sheets/detail/pretermbirth, 2018.

[2] "USAID,PCI,gapps and ACNM: Ethiopian profile of preterm and low birth weight prevention and care from Every PreemieSCALE," http://www.EveryPreemie.org, 2017.

[3] R. S. Moreira, L. C. Magalhães, and C. R. Alves, "Effect of preterm birth on motor development, behavior, and school performance of school-age children: a systematic review," Jornal de Pediatria, vol. 90, no. 2, pp. 119-134, 2014.

[4] "American College of Obstetrician and Gynecologist( FAQ008); Preterm(premature) labor and birth [Internet]," November, 2017.

[5] Dominique Haumont LZaSM, "The situation and the challenges with regard to preterm birth in Europe," 2012.

[6] M. E. Ahumada-Barrios and G. F. Alvarado, "Risk Factors for premature birth in a hospital," Revista Latino-Americana de Enfermagem, vol. 24, Article ID e2750, 2016.

[7] R. Alijahan, S. Hazrati, M. Mirzarahimi, F. Pourfarzi, and P. A. Hadi, "Prevalence and risk factors associated with preterm birth in Ardabil, Iran," Iranian Journal of Reproductive Medicine, vol. 12, no. 1, pp. 47-56, 2014.

[8] C. A. Iyoke, L. O. Lawani, E. C. Ezugwu, K. K. Ilo, G. C. Ilechukwu, and I. N. Asinobi, "Maternal risk factors for singleton preterm births and survival at the university of nigeria teaching hospital, Enugu, Nigeria," Nigerian Journal of Clinical Practice, vol. 18, no. 6, pp. 744-750, 2015.

[9] P. Wagura, A. Wasunna, A. Laving, D. Wamalwa, and P. Ng'ang'a, "Prevalence and factors associated with preterm birth at kenyatta national hospital," BMC Pregnancy and Childbirth, vol. 18, no. 107, 2018.

[10] L. Lu, Y. Qu, J. Tang, D. Chen, and D. Mu, "Risk factors associated with late preterm births in the underdeveloped region of China: a cohort study and systematic review," Taiwanese Journal of Obstetrics and Gynecology, vol. 54, no. 6, pp. 647-653, 2015.

[11] K. Abu Hamad, Y. Abed, and B. Abu Hamad, "Risk factors associated with preterm birth in the Gaza Strip: hospital-based case-control study," Eastern Mediterranean Health Journal, vol. 13, no. 5, pp. 1132-1141, 2007.

[12] T. B. Temu, G. Masenga, J. Obure, D. Mosha, and M. J. Mahande, "Maternal and obstetric risk factors associated with preterm delivery at a referral hospital in northern-eastern Tanzania," Asian Pacific Journal of Reproduction, vol. 5, no. 5, pp. 365-370, 2016.

[13] N. Morisaki, G. Togoobaatar, J. P. Vogel et al., "Risk factors for spontaneous and provider-initiated preterm delivery in high and low Human Development Index countries: a secondary analysis of the World Health Organization Multicountry Survey on Maternal and Newborn Health.," BJOG: An International Journal of Obstetrics \& Gynaecology, vol. 121, pp. 101-109, 2014.
[14] K. Gebreslasie, "Preterm birth and associated factors among mothers who gave birth in gondar town health institutions," Advances in Nursing, vol. 2016, Article ID 4703138, 5 pages, 2016.

[15] Z. Z. Hidayat, E. A. Ajiz, A. Achadiyani, and S. R. Krisnadi, "Risk factors associated with preterm birth at hasan sadikin general hospital in 2015," Open Journal of Obstetrics and Gynecology, vol. 06, no. 13, pp. 798-806, 2016.

[16] N. R. van den Broek, R. Jean-Baptiste, J. P. Neilson, and S. M. Hawkins, "Factors associated with preterm, early preterm and late preterm birth in Malawi," PLoS ONE, vol. 9, no. 3, p. e90128, 2014.

[17] N. Tehranian, M. Ranjbar, and F. Shobeiri, “The prevalence rate and risk factors for preterm delivery," Iran. Journal of Midwifery and Reproductive Health, vol. 4, no. 2, pp. 600-604, 2016.

[18] S. E. Simonsen, J. L. Lyon, J. B. Stanford, C. A. Porucznik, M. S. Esplin, and M. W. Varner, "Risk factors for recurrent preterm birth in multiparous Utah women: a historical cohort study," BJOG: An International Journal of Obstetrics \& Gynaecology, vol. 120, no. 7, pp. 863-872, 2013.

[19] I. Bekele, T. Demeke, and K. Dugna, "Prevalence of preterm birth and its associated factors among mothers delivered in jimma university specialized teaching and referral hospital, jimma zone, oromia regional state, South West Ethiopia," Journal of Women's Health Care, vol. 06, no. 01, article no. 356, 2017.

[20] J. He, R. Ramakrishnan, Y. Lai et al., "Predictions of preterm birth from early pregnancy characteristics: born in guangzhou cohort study," Journal of Clinical Medicine, vol. 7, no. 8, p. 185, 2018.

[21] X. K. Xu, Y. A. Wang, Z. Li, K. Lui, and E. A. Sullivan, "Risk factors associated with preterm birth among singletons following assisted reproductive technology in Australia 20072009-a population-based retrospective study," BMC Pregnancy and Childbirth, vol. 14, no. 1, article no. 406, 2014.

[22] Embargo, "Preterm birth now leading global killer of young children more than 3,000 children die daily from preterm birth complications," World Prematurity Day, 2014.

[23] UNICEF, "For Every Child," https://unicefethiopia.org/2013/11/ 16/preterm-babies-may-be-saved-with-simple-inexpensivemeasures/, November 2013.

[24] J. C. Hauth, R. L. Goldenberg, W. W. Andrews, M. B. Dubard, and R. L. Copper, "Reduced incidence of preterm delivery with metronidazole and erythromycin in women with bacterial vaginosis," The New England Journal of Medicine, vol. 333, no. 26, pp. 1732-1736, 1995.

[25] R. Romero, A. Conde-Agudelo, E. Da Fonseca et al., "Vaginal progesterone for preventing preterm birth and adverse perinatal outcomes in singleton gestations with a short cervix: a metaanalysis of individual patient data," Obstetric Anesthesia Digest, vol. 38, no. 4, pp. 220-221, 2018.

[26] M. B. Shetty, K. B. M., M. Malyala, A. Swarup, D. S. Pathadan, and S. Pocha, "Preterm birth: associated risk factors and outcome in tertiary care center," International Journal of Reproduction, Contraception, Obstetrics and Gynecology, vol. 6, no. 8, pp. 3271-3274, 2017.

[27] A. Butali, C. Ezeaka, O. Ekhaguere et al., "Characteristics and risk factors of preterm births in a tertiary center in Lagos, Nigeria," Pan African Medical Journal, vol. 24, 2016.

[28] WHO, "Wold health organization updates fact sheet on Preterm birth 16 November 2017," https://communitymedicine4asses. wordpress.com/2017/11/18/who-updates-fact-sheet-on-preterm -preterm-birth-16-november-2017/. 
[29] R. T. Souza, J. G. Cecatti, R. Passini et al., "The burden of provider-initiated preterm birth and associated factors: evidence from the brazilian multicenter study on preterm birth (EMIP)," PLoS ONE, vol. 11, no. 2, Article ID e0148244, 2016.

[30] T. Bekele, A. Amanon, and K. Z. Gebreslasie, "Preterm birth and associated factors among mothers who gave birth in Debremarkos Town Health Institutions, 2013 institutional based cross sectional study," Gynecology \& Obstetrics, vol. 5, no. 5, article 292, pp. 1-5, 2015.

[31] H. G. Mengesha, W. T. Lerebo, A. Kidanemariam, G. Gebrezgiabher, and Y. Berhane, "Pre-term and post-term births: predictors and implications on neonatal mortality in Northern Ethiopia," BMC Nursing, vol. 15, no. 1, article 48, 2016.

[32] M. Dayanithi, "Low birth weight and premature births and their associated maternal factors," International Journal of Community Medicine And Public Health, vol. 5, no. 6, pp. 2277$2285,2018$. 


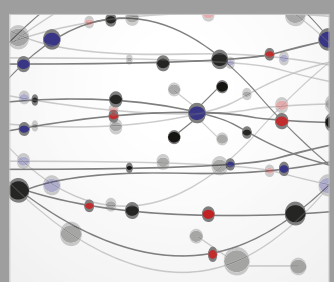

The Scientific World Journal
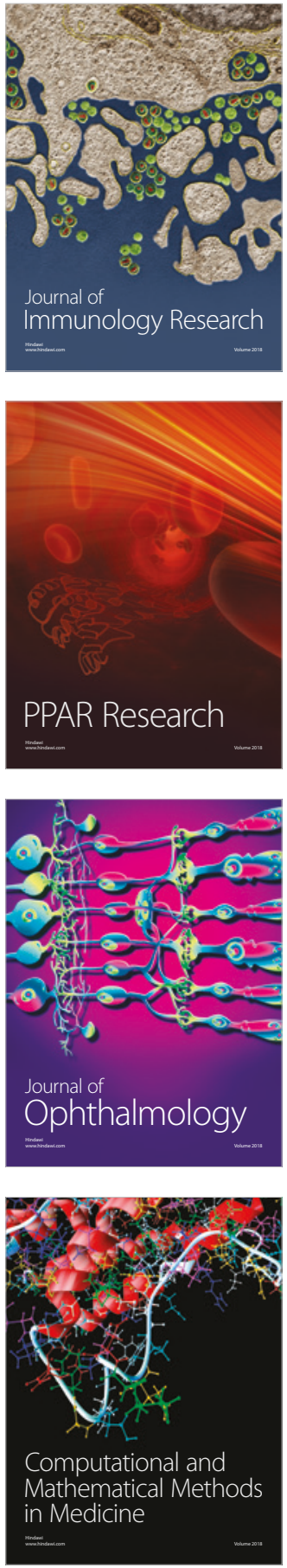

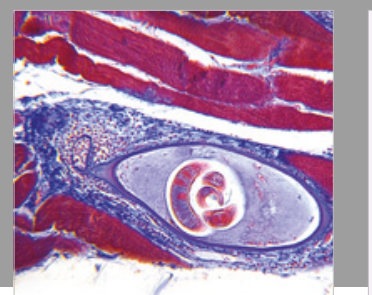

Gastroenterology Research and Practice

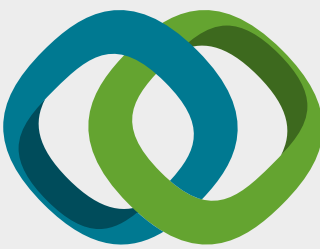

\section{Hindawi}

Submit your manuscripts at

www.hindawi.com
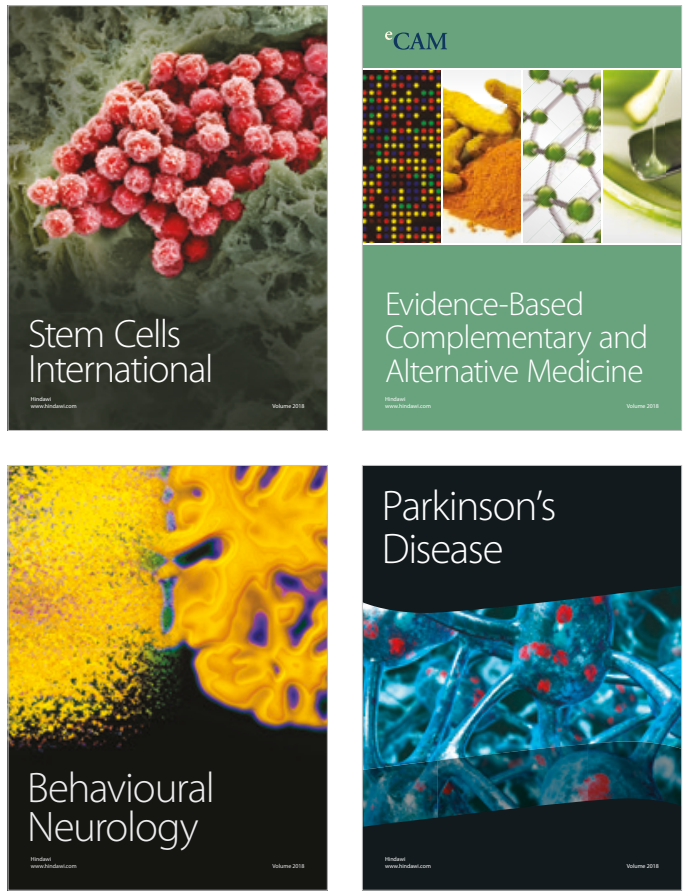

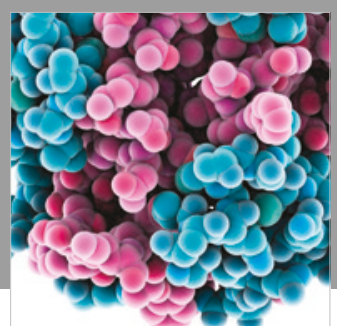

ournal of

Diabetes Research

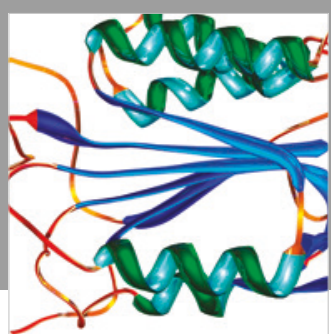

Disease Markers
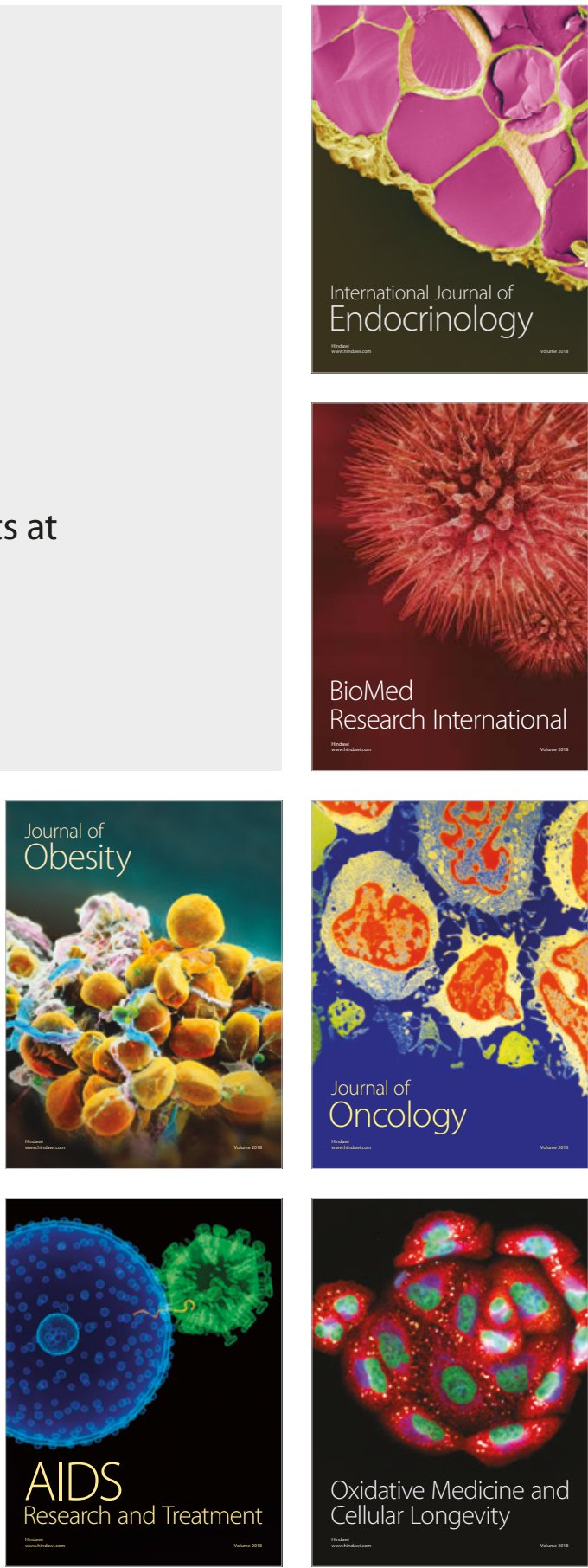